\title{
Systemic Modulation of Peripheral Eosinophilia (Air Pouch Model) in Schistosoma mansoni Infection
}

\author{
RG Pacheco, HL Lenzi*/+
}

\begin{abstract}
Clínica Médica B, Departamento de Medicina Geral, Hospital Universitário Gaffree e Guinle, Universidade do Rio de Janeiro, Rua Mariz e Barros 775, 20270-020 Rio de Janeiro, RJ, Brasil *Departamento de Patologia, Instituto Oswaldo Cruz, Av. Brasil 4365, 21045-900 Rio de Janeiro, RJ, Brasil
\end{abstract}

\begin{abstract}
Schistosoma mansoni infection induces in their hosts a marked and sustained eosinophilia, which is influenced or modulated by complex mechanisms, that vary according to the phase of infection. To address this phenomenon, we used the air pouch (AP) model in control and infected Swiss webster mice, analyzing the cellular, tissue response and local expression of adhesion molecules [CD18 ( $\beta_{2}$-chain), CD44, ICAM-1 (CD54), L-selectin (CD62L), CD49d ( $\alpha_{4}$-chain), LFA1 (CD11a)]. Infected animals were studied at 3 (pre-oviposition phase), 7 (acute phase), and 14 (chronic phase) weeks after infection (5-6 mice/period of infection). Normal mice were age-matched. Results showed that after egg stimulation, compared with matched controls, the infected mice, at each point of infection, showed a lower eosinophil response in the acute ( 7 weeks) and chronic phase (14 weeks) of infection. However, when the infected mice were in pre-oviposition phase (3 weeks) their eosinophil response surpassed the control ones. In the AP wall of infected mice, a significant decrease in the expression of ICAM-1 and CD44 in fibroblastic-like cells and a reduction in the number of CD18 and CD11a in migratory cells were observed. The other adhesion molecules were negative or weakly expressed. The results indicated that in the air pouch model, in S. mansoni-infected mice: (1) eosinophil response is strikingly down-regulated, during the acute ovular phase; (2) in the pre-oviposition phase, in contrast, it occurs an up-regulatory modulation of eosinophil response, in which the mechanisms are completely unknown; (3) in the chronic phase of the infection, the down modulation of eosinophil response is less pronounced; 4) Down-regulation of adhesion molecules, specially of ICAM-1 appear to be associated with the lower eosinophil response.
\end{abstract}

Key words: air pouch - adhesion molecules - Schistosoma mansoni egg - eosinophil - inflammation

Although the eosinophil was described more than one hundred years ago, its actual functions are still not well understood (Wardlaw et al. 1995). A hallmark of some allergic, parasitic, neoplastic, idiopathic and other diseases, eosinophil has been attributed to beneficial as well as harmful functions (Capron 1992, Tagboto 1996). Not withstanding from the ability to kill helminths to the destructive actions in asthma, eosinophil is a complex and mysterious cell. In parasitic diseases, as in schistosomiasis mansoni, eosinophilia is dependent on antigens secreted by eggs through the pores of the egg shell (SEA) (Race et al. 1969, Sher et al. 1990). The bone marrow and the blood eosinophilia peak, respectively, by the fifth and seventh week after the infection, and have been attributed to the en-

This work was supported by Fundação Oswaldo Cruz. ${ }^{+}$Corresponding author. Fax: +55-21-590.3495

Received 3 September 1997

Accepted 30 September 1997 hanced production of interleukin-5. Other primordial precursors stimulating cytokines are also involved in the eosinophilic pathway as the stem cell factor, IL-1, IL-3, GM-CSF, and G-CSF (Clutterbuck et al. 1989, Weller 1992).

The eosinophil is one of the most frequent cellular component of the most important lesion of schistosomiasis, the granuloma (Warren 1972). Even present in high number, the eosinophil is not a sine qua non condition for granuloma development (Sher et al. 1990). The acute eosinophil cellular response to eggs, and its contribution to the granuloma formation is not a well studied field. The murine experimental Schistosoma mansoni infection induces, as the infection ages, a modulatory mechanism that lower the hypersensitivity response to eggs (Andrade \& Warren 1964, Domingo $\&$ Warren 1968, Boros et al. 1975). Schistosomiasis mansoni has been characterized by a chronological change in cytokine expression of Th1 and Th2 subsets (Pearce et al. 1991, Chensue et al. 1993). These changes are involved in the modulatory process, and to IL-10 has been attributed a 
pivotal role in these mechanisms (Stadecker 1994). We have previously shown, in the air pouch model, that $S$. mansoni egg induces, after 6-8 $\mathrm{hr}$ of stimulation, an acute intra air pouch eosinophil wave (Pacheco \& Lenzi 1993).

In order to get a better insight of the eosinophil participation in schistosomiasis mansoni infection, we performed a sequential study of the eosinophil migration into the air pouch model, after $8 \mathrm{hr}$ of egg stimulation, in mice at 3 (pre-oviposition phase), 7 (acute phase) and 14 (chronic phase) weeks after infection. This study was complemented by an immunofluorescence analysis of the expression of adhesion molecules at the air pouch covering, using monoclonal antibodies.

\section{MATERIALS AND METHODS}

S. mansoni infection - Five days old Swiss webster mice were infected by percutaneous exposure to 70 cercariae of the Belo Horizonte isolate of S. mansoni (Paraense \& Corrêa 1963, 1981).

Air pouch - It was prepared as described and reported by Edwards et al. (1981) with modifications. Briefly, one day before the beginning of the air pouch production, the fur on the dorsum of each mouse was shaved with an electric clipper. On day zero, $5 \mathrm{ml}$ of sterile air were injected subcutaneously into the same region of mice to form the pouches. In order to keep them patent, on day 3, they were replenished with $2 \mathrm{ml}$ of sterile air. All experimental procedures to the air pouch production were carried out under light ether anesthesia.

The sterile air was obtained in a laminar flow station by filtration through a Millipore $(0.22 \mu \mathrm{m})$ directly into a syringe of $10 \mathrm{ml}$. On day 8 , the pouches were stimulated with eggs or endotoxinfree saline, using individual sterile needles.

Egg purification - Mice with 8-12 weeks of infection, as before, were killed by an overdose of ether inhalation. The intestines were collected, opened, water cleaned, chopped and left to stay in a beaker overnight at room temperature. The material was processed in a blender, for a few seconds, in $1.7 \%$ saline, filtered through gradually smaller serial size 48, 80, 100, 150 steel mesh sieves and the eggs retained in a size 325 mesh sieve (Bertel, Caieiras, SP, Brasil). The eggs sedimented for one hour and half at $4^{\circ} \mathrm{C}$. Finally, the eggs were collected and centrifuged at $150 \mathrm{~g}$ for 30 seconds, several times until purification. The pellet containing eggs was kept overnight in an ice bath at $0-4{ }^{\circ} \mathrm{C}$ until use.

Injection of eggs - The eggs were adjusted to a $5000 / \mathrm{ml}$ concentration in $0.9 \%$ endotoxin-free saline and injected by using an insulin needle and syringe. The same number of matched control animals received endotoxin-free saline.
Cell harvesting - The animals were killed by an overdose of ether inhalation, and $1 \mathrm{ml}$ of phosphate-buffer saline (PBS) was injected into the air pouches. The pouches were gently massaged and opened, at their caudal portion. The material was collected with a Pasteur pipette and maintained in ice bath until cell counting and cytocentrifugation.

Cell counting - Total cell count was done in Neubauer chamber. The absolute eosinophil number was obtained from the percentage of eosinophil in the centrifuged slide, and the total cell count.

Cytospin preparation - The collected materials from the air pouches were cytocentrifuged (Citospin, Incibras, Brasil) during $10 \mathrm{~min}$, at $640 \mathrm{rpm}$. The slides were stained by May-Grünwald method, and 200-400 viable cells per slide were counted.

Experimental design - Infected Swiss webster mice of both sexes, after 2 (pre-oviposition phase), 6 (acute phase) and 13 (chronic phase) weeks of infection (5-6 mice/group) were picked randomly for the air pouch production. After 8 days, the air pouches were stimulated with 2,500 eggs diluted in endotoxin-free saline; $8 \mathrm{hr}$ later, mice were killed and intrabursal cells were collected. The same number of matched controls which received only endotoxin-free saline were also analyzed.

Histopathology - The whole air pouch were fixed in Formalin Millonig (Carson et al. 1973), at $\mathrm{pH}$ 7.0-7.4. The samples were embedded in paraffin and the slides stained with hematoxylin/eosin, PAS-Alcian blue pH 1.0 and 2.5, Lennert "s Giemsa, Evans blue for eosinophils detection using confocal microscopy (Lenzi et al. 1996) , in LSM-410 (Zeiss).

Direct immunofluorescence - Adhesion molecules - A small piece of the cephalic portion of the air pouch attached to the skin, was immediately frozen in liquid nitrogen and maintained at $20^{\circ} \mathrm{C}$ until the cryostat slides preparation. The slides were fixed with cold acetone and conserved at $20^{\circ} \mathrm{C}$ until the immunofluorescence studies. Monoclonal antibodies (PharMingen) diluted in a 1:15 ratio to ICAM-1 (CD54), CD44, CD18 ( $\beta_{2}$ chain), LFA1 (CD11a), L-Selectin (CD62L), LEPAM (CD49d) were used. Briefly after rehydration with PBS, the slides were blocked with a solution of $1 \%$ BSA and $3 \%$ powder skimmed milk. The diluted $\mathrm{mAb}$ was maintained in contact with slides during $45 \mathrm{~min}$ at $37^{\circ} \mathrm{C}$. The slides were stained, mounted in glycerol with p-phenylenediamine and cover glass and examined in the same day in a microscope for immunofluorescence (Zeiss-Germany).

Data analysis - The data are summarized as mean $\pm \mathrm{SD}$, and were analyzed by the statistical GraphPad InStat software package, version 2.0 (Graph Pad Software, San Diego, CA, USA). 
Statistical significance was determined by using unpaired $t$-test and significance was determined with the use of $p$ values $<0.05$.

\section{RESULTS}

Absolute eosinophil number - Saline stimulation elicited the lowest eosinophil responses, even in infected mice. After egg stimulation, compared with matched controls, the infected mice, in each point of infection, showed a lower eosinophil response in the acute (7 weeks) and chronic phase (14 weeks) of infection. However, when the infected mice were in pre-oviposition phase (3 weeks), their eosinophil response surpassed the control ones (Fig. 1). Although the eosinophil levels decreased in normal and infected mice, at the 7th week of age/infection, the normal mice showed a continuous increase of total cell count during the experiment. Otherwise, the infected ones presented always lower total cell count than the controls, specially at the 7th week of infection (Fig. 2)

Eosinophil percentage - Differently from the absolute number, the eosinophil percentage, as a rule, was higher with saline than with egg stimulation. The infected mice always showed a higher eosinophil percentage than control mice when the same stimulus (saline or egg) and the same age/ time of infection were compared. After saline stimulation, the eosinophil percentage enhanced gradually as the mice were aging (Fig. 3).

Histopathology - After egg stimulation, the neutrophil infiltration, in the air pouch wall, was higher in normal mice than in infected ones, in all studied points. Otherwise, the eosinophil infiltration was much higher in normal mice at the 3 rd week. At the

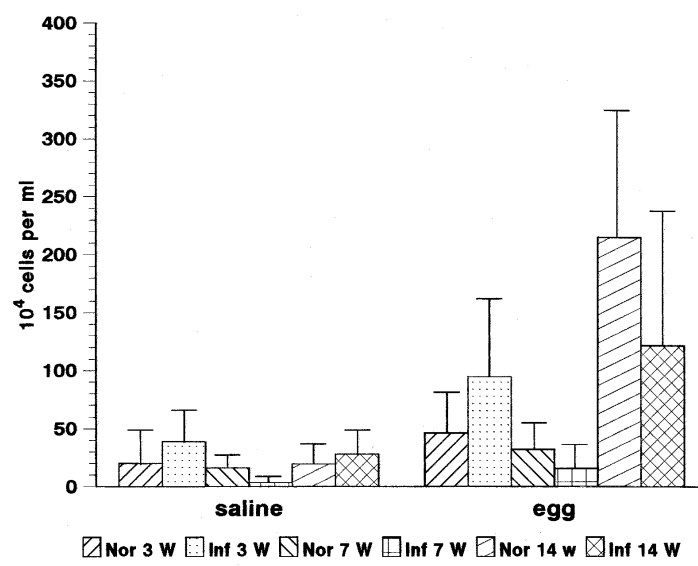

Fig. 1: absolute eosinophil number, $8 \mathrm{hr}$ after air pouch stimulation with LPS-free saline $0.9 \%$ or 2,500 Schistosoma mansoni eggs in infected mice at the 3rd, 7th and 14th weeks of infection and in matched controls. Mean of 5-6 mice after counting 200-400 cells in centrifuged slides stained with Mäy-Grünwald stain. Nor: normal mice; Inf: infected mice.

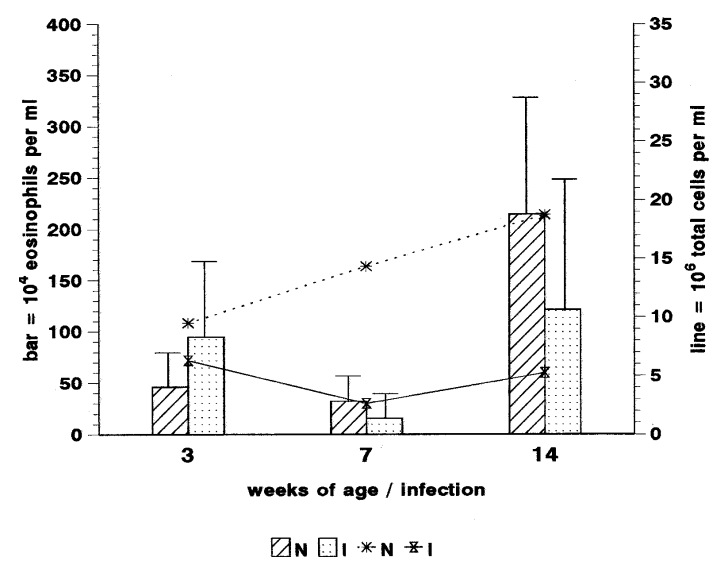

Fig. 2: total cell count (line) and absolute (bar) counts in the air pouches of normal $(\mathrm{N})$ and Schistosoma mansoni-infected-mice (I), $8 \mathrm{hr}$ after $S$. mansoni egg stimulation, during different times of age/infection.

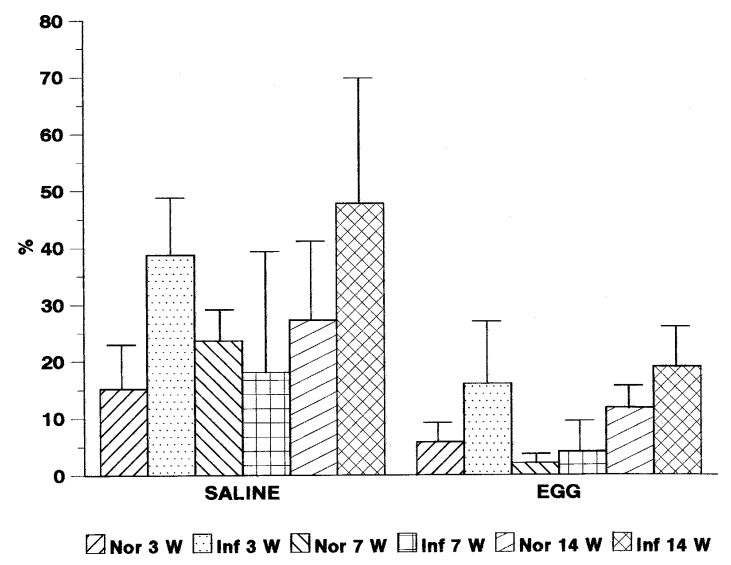

Fig. 3: eosinophil percentage, $8 \mathrm{hr}$ after air pouch stimulation, with LPS-free saline $0.9 \%$ or 2,500 Schistosoma mansoni eggs in infected mice at the 3rd, 7th and 14th weeks of infection and in matched controls. Mean of 5-6 mice after counting 200-400 cells in centrifuged slides stained with Mäy-Grünwald stain. Nor: normal mice; Inf: infected mice.

7th and 14th weeks of infection, the eosinophil infiltration was similar to the matched controls. The normal mice had few eosinophil cells in the bone marrow, even when the eosinophil infiltration in the air pouch wall was pronounced (Fig. 4A, B). The infected mice on the contrary, mainly in the acute phase ( 7 weeks) showed a striking increase in the bone marrow eosinophil lineage, which was not accompanied by proportional eosinophil infiltration in the air pouch wall (Fig. 4C, D).

Immunohistology - The expression of adhesion molecules, in different structural components of the air pouch, was always compared between control and infected mice with 7 and 14 weeks of infection. 

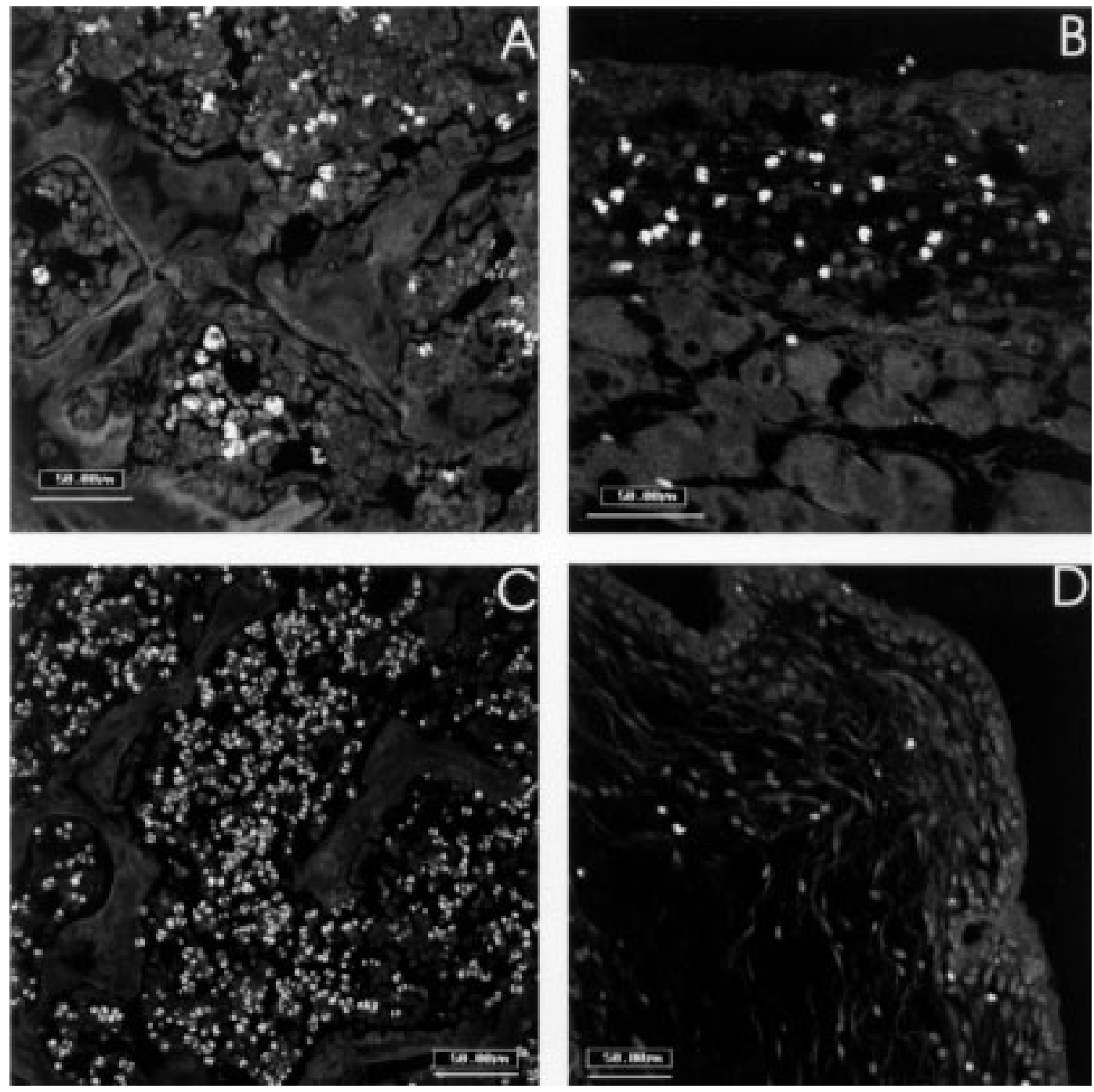

Fig. 4: eosinophil population in the bone marrow and air pouch wall as analyzed by confocal microscope using Evans blue staining. Three week-old normal mouse (A: bone marrow; B: air pouch wall); 7 week-infected mouse (C: bone marrow; D: air pouch wall).

L-selectin (CD62L), CD49d (integrin $\alpha_{4}$-chain) and CD11a (LFA-1) did not show significative difference between infected and control mice, and no one correlation could be drawn relating to the eosinophil migration.

CD18 labeled weakly fibroblasts of the air pouch wall of all groups, and was more intense on migrating cells, which were more numerous in air pouch of control mice stimulated with eggs (Fig. 5A). CD54 (ICAM-1), after egg stimulation, marked diffuse and intensely all the air pouch wall layers of the control mice (Fig. 5B), showing impressive decrease in infected ones. This different behavior of CD54 expression was also detected in vascular endothelium of arteries, veins and capil- laries. CD44 showed similar staining characteristics as CD54 (ICAM-1), except that it was more intense on fibroblasts and in the innermost layers of the air pouch wall (Fig. 5C, D). Frequently, CD54 and CD44 presented a cadherin-like pattern of immunofluorescence (Table). The lowest expression of CD18, CD54, and CD44 was coincident with the decrease in the number of eosinophils inside the air pouch.

\section{DISCUSSION}

This study showed that $S$. mansoni infected mice modulated the acute eosinophil response, depending on the time of the infection. This phenomenon was observed using the air pouch model stimulated with purified S. mansoni eggs. In the 

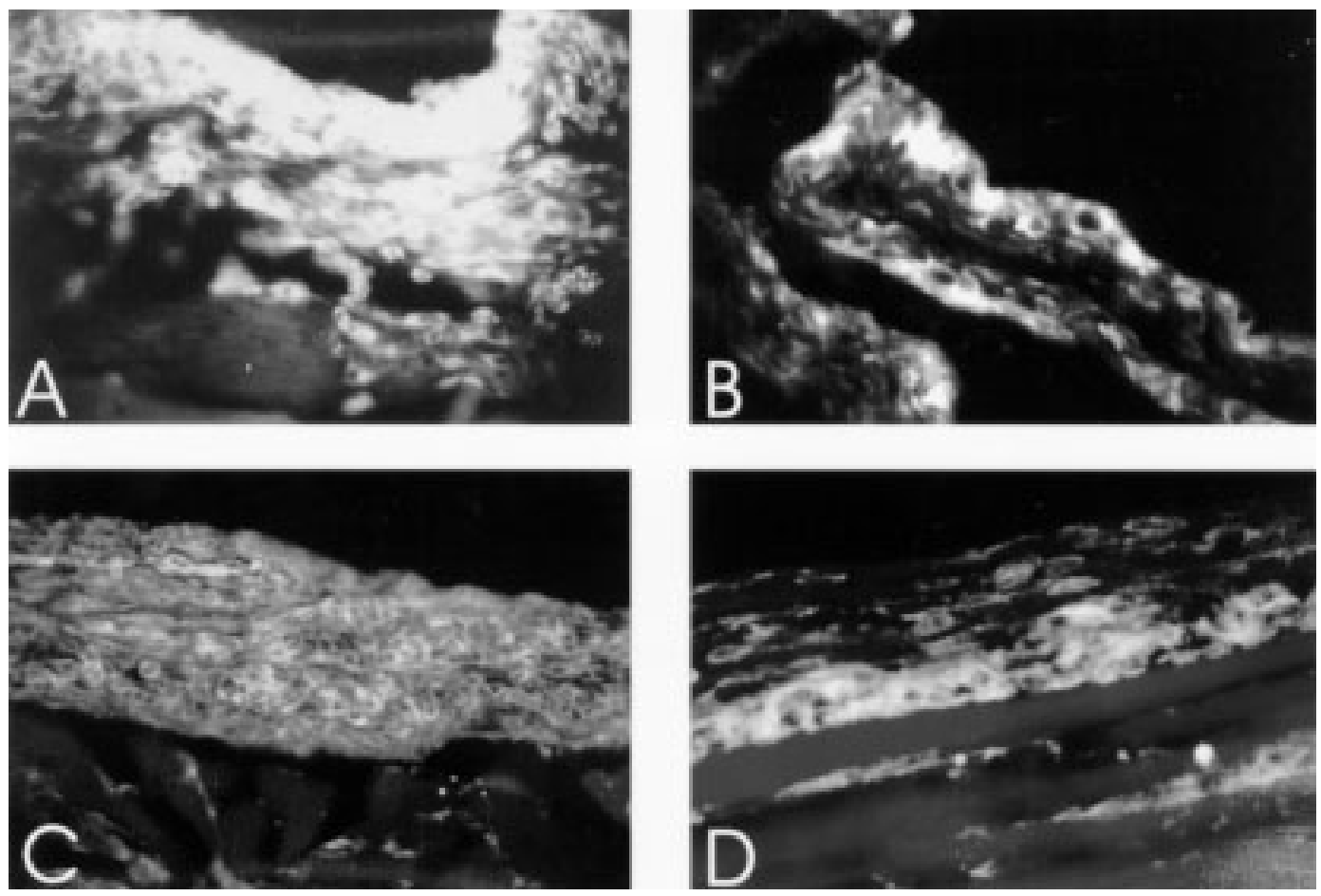

Fig. 5: adhesion molecules expression, in air pouch wall of normal and infected mice, after $8 \mathrm{hr}$ of stimulation. Air pouch of normal mouse (seven weeks old) with intense CD18 ${ }^{+}$cells (A). Expression of ICAM-1 in the air pouch linning of normal mouse (seven weeks old) (B). Diffuse cadherin-like pattern of CD44 in normal (C), compared with weak distribution and fusiform pattern in fibroblasts of the air pouch wall of 14 week-infected mice (D).

TABLE

Expression of adhesion molecules in air pouch wall of infected compared with control mice, $8 \mathrm{hr}$ after Schistosoma mansoni egg stimulation

\begin{tabular}{lcc}
\hline & \multicolumn{2}{c}{ Time of Infection } \\
\cline { 2 - 3 } Adhesion molecules ${ }^{a}$ & 7 weeks & 14 weeks \\
\hline CD62L (L-selectin) & - & - \\
CD49d (integrin $\alpha_{4}$-chain) (migrating cells) & $\uparrow$ & $\uparrow$ \\
CD11a (LFA-1) (mast cells) & $=$ & nd \\
CD18 (migrating cells) & $\downarrow \downarrow \downarrow$ & $\downarrow \downarrow \downarrow$ \\
CD54 (ICAM-1) & $\downarrow \downarrow \downarrow$ & $\downarrow \downarrow \downarrow$ \\
CD44 & $\downarrow \downarrow$ & $\downarrow \downarrow$ \\
\hline
\end{tabular}

$a$ : direct immunofluorescence; (-) negative in control and infected mice; (=) no difference; $\downarrow$ decrease (different intensities); $\uparrow$ increase; (nd) not done.

pre-oviposition phase of the infection occurred an up-modulation, while in the acute (7 weeks) and chronic (14 weeks) phases, the eosinophil response was down-modulated. The literature has emphasized multiple putative immunoregulatory mechanisms, during the course of $S$. mansoni infection, such as suppressor $\mathrm{T}$ cell activity (Colley et al. 1978), adherent phagocytic suppressor cells (Todd et al. 1979), serum-mediated suppression (Colley et al. 1977, Ottesen \& Poindexter 1980), circulating immune complexes (Goes et al. 1991) and idiotypic/anti-idiotypic interactions, involving also anti-idiotypic T lymphocytes (Lima et al. 1986, Powell \& Colley 1987, Parra et al. 1988, 1991). However, all these mechanisms are related to the pos-oviposition phases of the infection, and probably some of them interfere with eosinophil response. Authors (Colley 1972, Mahmoud et al. 
1975, Lenzi \& Lenzi 1990) have shown that the eosinophil number fluctuate, during the $S$. mansoni infection, in distinct compartments (bone marrow, blood, peritoneal cavity, milky spots and organs with egg embolism), reaching higher number in the acute phase, with high levels persisting even in chronic phase of infection. Our results showed that the down modulation of the intrabursal eosinophil response was coincident with the largest systemic and peri-ovular eosinophilia (around 7 weeks), indicating, two important aspects: (1) The downmodulation is independent of eosinophil production and circulation, not being due to a lack of eosinophils supply; (2) It is a striking modulation because it occurs when the peripheral and central (bone marrow) eosinophil levels are very high (Fig. $4 \mathrm{C})$.

The data also suggest that the modulatory mechanisms act, at least, on two levels: endothelium, and air pouch wall. This hypothesis was based on the decrease of the following adhesion molecules: (a) ICAM-1 in vascular endothelium of arteries, veins and capillaries that are adjacent to the air pouch wall and (b) ICAM-1 and CD44 in the air pouch wall. These events could interfere with leukocyte-endothelial recognition phase of the acute inflammatory response, decreasing the number of migrating cells, detected by anti-CD18. Other additional mechanisms can contribute to explain the down-modulation in the acute phase: (1) massive and compartmentalized mobilization of blood eosinophils to organs that suffer egg embolism; (2) large release of soluble adhesion molecules to the circulation, blocking leukocyte-endothelial interactions (Evan Secor et al. 1994); (3) compartmentalized response of the air pouch to egg stimulation. Using protein A-stimulated air pouch, Teixeira et al. (1994) showed a decrease of polimorphonuclear migration in mice infected with S. mansoni, mainly in the acute phase of the infection. The same phenomenon was observed by Abath et al. (1988), in acute Trypanosoma cruzi infected mice; and (4) alterations of eosinophil capabilities by soluble factors. Dessein et al. (1984) showed that the "Eosinophil Cytotoxicity Enhancing Activity" (ECEA) released by blood mononuclear cells was suppressed in most patients, except in those with heavy Schistosoma infections, including patients with hepatosplenomegaly.

As is shown in Fig. 1, when the intrabursal eosinophilia of control versus infected mice was compared in post-oviposition phases, always the infected groups attained lower number of eosinophils by cytological analysis. However, when the eosinophil levels from animals with 7 weeks were compared with ones of 14 weeks of infection, there was an absolute and relative increase in the later ones (Figs 1 and 3). This event suggest the existence of different and unknown control mechanisms on the inflammatory reaction in the acute and chronic phases of the schistosomal infection. Lenzi (1991) has shown that in the chronic phase of infection, when compared with the acute one, occurred a decrease of eosinopoiesis, megakaryopoiesis, and lymphopoiesis, and an increase in the tissue mast and plasma cells, indicating changes in growth factors and cytokines networks during the course of the infection. Our data also showed an enhance of the eosinophil migratory capability to the air pouch, with advancing age, better observed in control group, by the increase of the eosinophil percentage, after saline stimulation (Fig. 3). The age and chronic-infected-related changes do not involve defects in the functions of $\mathrm{T}$ cells, including cytokine production (Engwerda et al. 1996). Actually, the studied animals were in the range of young adults (Hobbs et al. 1993). It is interesting to note that, in the infected mice, the eosinophil response inside the air pouch was inversely related to the systemic eosinophil supply.

The up-modulation of the intrabursal eosinophilia detected in the pre-oviposition phase of $S$. mansoni infection, could be due to lack of immune modulation that is part of the acute syndrome (Cheever 1992). Indeed, the first peak of blood eosinophilia that occurs in the pre-oviposition phase is not affected by T-lymphocyte depletion (Colley et al. 1973, Fine et al. 1973, Lenzi et al 1987). .

In conclusion, the results of this study, using the air pouch model, showed that the acute eosinophil response is differently modulated, according to the time of $S$. mansoni infection. Bursal (air pouch) and endothelial cell-derived adhesion molecules, such as ICAM-1 (and CD44 ?) appear to play a prominent role. The egg is the main factor that switch, not only the immune, but also the acute inflammatory response. Further comprehensive studies using intercrines a $(\mathrm{C}-\mathrm{X}-\mathrm{C})$, and $\beta$ (C-C) subfamilies (Oppenheim et al. 1991), affiliated with the recruitment phase of the inflammatory response should be applied to a better elucidation of the acute tissue eosinophilia.

\section{REFERENCES}

Abath F, Montenegro S, Carvalho A 1988. In vivo leukocyte chemotaxis during the development of acute experimental Trypanosoma cruzi infection. Braz J Medical Biol Res 21: 1013-1014.

Andrade Z, Warren K 1964. Mild prolonged schistosomiasis in mice: alterations in host response with time and the development of portal fibrosis. Trans $R$ Soc Trop Med Hyg 58: 53-57.

Boros D, Pelley R, Warren K 1975. Spontaneous modulation of granulomatous hypersensitivity in Schisto- 
somiasis mansoni. J Immunol 114: 1437-1441.

Capron M 1992. Dual function of eosinophils in pathogenesis and protective immunity against parasites. Mem Inst Oswaldo Cruz 87 (Suppl V): 83-89.

Carson FL, Martin JH, Lynn JA 1973. Formalin fixation for electron microscopy. A re-evaluation. Am J Clin Pathol 59: 365-373.

Cheever A 1992. Pathogenesis of Schistosoma mansoni infection. Mem Inst Oswaldo Cruz 87 (Suppl IV): 337-340.

Chensue S, Warmington K, Hershey S, Terebuh P, Othman M, Kunkel S 1993. Evolving T cell responses in murine schistosomiasis. Th2 cells mediate secondary granulomatous hypersensitivity and are regulated by $\mathrm{CD} 8+\mathrm{T}$ cells in vivo. $J$ mmunol 151: 1391-1400.

Clutterbuck E, Hirst E, Sanderson C 1989. Human interleukin-5 (IL-5) regulates the production of eosinophils in human bone marrow cultures: comparison and interaction with IL-1, IL-3, IL-6, and GMCSF. Blood 73: 1504-1512.

Colley DG 1972. Intradermal immune response to a schistosomal egg antigen during experimental murine Schistosoma mansoni infection. Proc Soc Exp Biol Med 140: 772-775.

Colley DG, Hieny SE, Bartholomew RK, Cook JA 1977. Immune responses during human schistosomiasis mansoni. III. Regulatory effect of patients sera on human lymphocyte blastogenic responses to schistosomal antigen preparations. Am J Trop Med Hyg 26: 917-925.

Colley DG, Katz SP, Wikel SK 1973. Schistosomiais: An experimental model for the study of immunopathologic mechanisms which involve eosinophils. Adv Biosciences 12: 653-665.

Colley DG, Lewis FA, Goodname RW 1978. Immune responses during human schistosomiasis mansoni. IV. Induction of suppressor cell activity by schistosome antigen preparations and Concavalin A. $J$ Immunol 120: 1225-1232.

Dessein AJ, Lenzi HL, Bina JC, Carvalho EM, Weiser WY, Andrade ZA, David JR 1984. Modulation of eosinophil cytotoxicity by blood mononuclear cells from healthy subjects and patients with chronic schistosomiasis mansoni. Cell Immunol 85: 100-113.

Domingo E, Warren K 1968. Endogenous desensitization: changing host granulomatous response to schistosome eggs at different stages of infection with Schistosoma mansoni. Am J Pathol 52: 369-377.

Edwards J, Sedgwick A, Willoughby D 1981. The formation of a structure with the features of synovial lining by subcutaneous injection of air: an in vivo tissue culture system. J Pathol 134: 147-156.

Engwerda C, Fox B, Handwerger B 1996. Cytokine production by $\mathrm{T}$ lymphocytes from young and aged mice. J Immunol 156: 3621-3630.

Evan Secor W, dos Reis MG, Ramos EAG, Peixoto Matos E, Reis EAG, Carmo TMA, Harn jr., DA 1994. Soluble intercellular adhesion molecules in human schistosomiasis: correlation with disease severity and immunoregulated responses to egg antigens. Infec Immun 62: 2695-2701.
Fine DP, Buchanan RD, Colley DG 1973. Schistosoma mansoni infection in mice depleted of thymus-dependent lymphocytes. I. Eosinophilia and immunologic responses to a schistosomal egg preparation. Am J Pathol 71: 193-206.

Goes AM, Gazzinelli G, Rocha R, Katz N, Doughty BL 1991. Granulomatous hypersensitivity to Schistosoma mansoni egg antigens in human schistosomiasis. III. In vitro granuloma modulation induced by immune complexes. Am J Trop Med Hyg 44: 434-443.

Hobbs MV, Weigle WD, Nooman DJ, Torbett BE, McEvilly RJ, Kock RJ, Cardenas GJ, Ernst DN 1993. Pattern of cytokine gene expression by $\mathrm{CD} 4^{+} \mathrm{T}$ cells from young and old mice. J Immunol 150: 36023614.

Lenzi HL 1991. A dinâmica da resposta hematológica e celular na esquistossomose mansônica, com ênfase nas séries eosinofílica e mastocitária. Thesis. Universidade Federal do Minas Gerais, 580 pp.

Lenzi H, Lenzi J 1990. Comparative distribution of eosinophils in bone marrow, blood and peripheral cavity in murine schistosomiasis. Braz J Med Biol Res 23: 989-994.

Lenzi HL, Pelajo-Machado M, Caputo LFG, Vale BS 1996. Microscopia de varredura laser confocal: 2 Recursos técnicos e aplicações biomédicas. Newslab 18: 106-122.

Lenzi HL, Sobral ACL, Lenzi JA 1987. "In vivo” kinetics of eosinophils and mast cells in experimental murine schistosomiasis. Mem Inst Oswaldo Cruz 82 (Suppl IV): 67-76.

Lima MS, Gazzinelli G. Nascimento E, Parra JC, Montesano MA, Colley DG 1986. Immune responses during human schistosomiasis mansoni. Evidence for antiidiotypic T lymphocyte responsiveness. J Clin Invest 78: 983-988.

Mahmoud A, Warren K, Graham Jr R 1975. Antieosinophil serum and the kinetics of eosinophilia in schistosomiasis mansoni. J Exp Med 142: 560574.

Oppenheim JJ, Zacharae COC, Matsushima K 1991. Properties of the novel proinflammatory supergene "intercrine" cytokine family. Ann Rev Immunol 9: 617-648.

Ottesen EA, Poindexter RW 1980. Modulation of the host response in human schistosomiasis. II. Humoral factors which inhibit lymphocyte proliferative responses to parasite antigens. Am J Trop Med Hyg 29: 592-597.

Pacheco RG, Lenzi HL 1993. Air pouch kinetics after challenging with Schistosoma mansoni eggs. Abstr 153 , in Abstracts of $4^{\circ}$ International Symposium on Schistossomiasis, Rio de Janeiro.

Paraense WL, Corrêa LR 1963. Susceptibility of Australorbis tenagophilus to infection with Schistosoma mansoni. Rev Inst Med Trop São Paulo 5: 2329.

Paraense WL, Corrêa LR 1981. Observations on two biological races of Schistosoma mansoni. Mem Inst Oswaldo Cruz 76: 287-291.

Parra JC, Gazzinelli G, Goes AM, Moyes RB, Rocha R, Colley DG, Doughty BL 1991. Granulomatous hy- 
persensitivity to Schistosoma mansoni egg antigens in human schistosomiasis. II. In vitro granuloma modulation by polyclonal idiotypic antibodies. $J$ Immunol 147: 3949-3954.

Parra JC, Lima MS, Gazzinelli G, Colley DG 1988. Immune responses during human schistosomiasis mansoni. XV. Anti-idiotypic T cells can recognize and respond to anti-SEA idiotypes directly. $J$ Immunol 140: 2401-2405.

Pearce E, Caspar P, Grzych J, Lewis F, Sher A 1991. Downregulation of Th1 cytokine production accompanies induction of Th2 response by a parasitic helminth, Schistosoma mansoni. J Exp Med 173: 159-166.

Powell MR, Colley DG 1987. Anti-idiotypic T lymphocyte responsiveness in murine schistosomiasis mansoni. Cell Immunol 104: 377-385.

Race G, Michaels R, Larsh J, Matthews J 1969. Schistosoma mansoni eggs: an electron microscopic study of shell pores and microbarbs. Proc Soc Exp Biol Med 130: 990-992.

Sher A, Coffman RL, Hieny S, Scott P, Cheever AW 1990. Interleukin 5 is required for the blood and tissue eosinophilia but not granuloma formation induced by infection with Schistosoma mansoni. Proc
Natl Acad Sci USA 87: 61-65.

Stadecker M 1994. The shrinking schistosomal egg granuloma: how accessory cells control T cell-mediated pathology. Exp Parasitol 79: 198-201.

Tagboto S 1996. Interleukin-5, eosinophils and the control of helminth infections in man and laboratory animals. J Helminthol 69: 271-278.

Tood CW, Goodname RW, Colley DG 1979. Immune responses during human schistosomiasis mansoni. V. Suppression of schistosome antigen-specific lymphocyte blastogenesis by adherent/phagocytic cells. J Immunol 122: 1440-1446.

Teixeira K , Coutinho A, Montenegro S 1994. "In vivo" leukocyte chemotaxis in experimental mice Schistosoma mansoni infection. Rev Inst Med Trop $S$ Paulo 36: 283-285.

Wardlaw A, Moqbel R, Barry Kay A 1995. Eosinophils : biology and role in disease. Adv Immunol 60: 151-266.

Warren KS 1972. The immunopathogenesis of schistosomiasis: a multidisciplinary approach. Trans $R$ Soc Trop Med Hyg 66: 417-432.

Weller P 1992. Cytokine regulation of eosinophil function. Clin Immunol Immunopathol 62: S55-S59. 